\title{
A secondary School Teacher Fellow within a university chemistry department: the answer to problems of recruitment and transition from secondary school to University and subsequent retention?
}

\author{
Dudley E. Shallcross and Timothy G. Harrison \\ Bristol ChemLabS, School of Chemistry, University of Bristol, BS8 1TS, UK. \\ e-mail: d.e.shallcross@bris.ac.uk
}

Received 28 November 2006, accepted 4 December 2006

In the UK the changes that have taken place in secondary school science education over the last 20 years are considerable. The national curriculum for sciences has once again been changed and has just been introduced to the current Year 10 (fifteen year olds) in September 2006. The most recent AS/A level (exams at 18) syllabuses (now called specifications) were unitised in 2000 and are to be changed again for September 2008. The International Baccalaureate and School Diplomas are mooted to be the way that secondary education is heading. However, changes to the scheme of work in all science subjects has been a moving target where topics within a subject have been in and out and even changed from one science discipline to another during this turbulent period. A quandary indeed for a University Science Department to maintain congruence at the A level - year 1 undergraduate interface and allow students to have a smooth transition from secondary school or college to University (e.g. Rynne and Lambert, 1997). The School of Chemistry at Bristol University, like many others in the UK, have set up a teaching advisory board (TAB) comprising secondary school teachers, academics and other interested parties. The TAB has proved to be a very helpful mechanism for exchange of ideas but is limited in that secondary school teachers can usually only commit to one or two (unpaid) meetings a year, and the focus of each meeting must be narrow for it to achieve depth of investigation.

School-university transition is not the only problem that all University Science departments struggle with in the UK, retention and recruitment are also major items on the agenda. The well-publicised demise of several Chemistry Departments has highlighted the danger, and in recent years the need to raise the profile of Science, and in particular Chemistry and Physics, has been paramount (Woods and Morris, 2005). What can be done in response to such problems? Barnes (1999) suggested that academics should return to the classroom. Bristol ChemLabS has taken the step to recruit a School Teacher Fellow (STF), and here we outline the potential benefits to all concerned of recruiting a School Teacher Fellow.

\section{The desirable characteristics of a School Teacher Fellow}

Ideally, School Teacher Fellows (STFs) should be qualified and experienced secondary school teachers who would work in the University department of their specialism. Such persons should have already held some position of responsibility in the school's middle management so that the formality of meetings, giving presentations to peers, report writing and bid writing are not alien to them. They would also be used to working with groups of teachers other than those in their own schools. Their experience would, of course, be essential 
when advising on changes to course structures and how this may affect subject knowledge and transferable skills for a range of undergraduates and even postgraduates in a University department. It would be quite important, but not essential, that such teachers should already have strong links with the outreach activities already going on in the university department where they are to work. The STFs would be seconded from their schools for at least a year (see later) and would maintain strong links with those schools during the tenure of their post.

\section{The benefits of a School Teacher Fellow to the University Department}

\section{School-university transition and retention}

A School Teacher Fellow will know at least one of the examination boards' specifications and their own school's scheme of work derived from it in their subject particularly at A/AS level, and can advise departments on congruence between first year undergraduate courses and A level. A particular emphasis on advising on the practical skills base of new undergraduates is vital. The STF can also work closely with technical staff on matters of experiment design, and appropriateness of equipment and labelling. Ausubel (1968) encouraged us to ascertain what the learner already knows and to teach accordingly, the STF is the ideal source of this information.

A STF will draw the attention of university staff to differences in approach to the use of IUPAC nomenclature between schools and universities that may lead to serious difficulties for new undergraduates, and will be able to advise on labelling and appropriate naming.

A STF will know what modes of assessment will be familiar to students. Feedback to a teaching committee will ensure that students have ample training where required for new forms of assessment. It may be that the school-level methods of assessment, particularly in practicals, may be built on at the University.

STFs may act as supplementary tutors to students who are struggling with basic concepts from A level and those students recruited via access routes without A level, thereby supporting widening access. They may even take on a pastoral role, being more familiar with the students' prior experience and potential problems than any University lecturer. A STF may also be one of the first points of contact by undergraduates or postgraduates considering a career in teaching by providing accurate and up-to-date information about the profession and its working conditions, and may assist in arranging some relevant work experience/classroom observation.

\section{Recruitment}

STFs will know:

- the secondary school year and in particular when examinations occur. They will also know the difficulties in taking students out of school, and the timescale required to plan to do so. Therefore, recruitment and outreach events can be arranged to have maximum impact and appeal in terms of timing.

- what secondary school teachers are looking for during an outreach event. This is also true for CPD events for teachers.

STFs will themselves have wide experience with public engagement and may know about sources of funds and resources, particularly those that will fund public engagement activities. They can work with higher education colleagues in the preparation of articles on leading edge research at the appropriate levels for use in schools, for example articles prepared for journals such as Chemistry Review or Education in Chemistry. This also applies to postgraduates who wish to write or give presentations to secondary schools where the use of appropriate language level for age group can make or break an event. They can also work closely with 
research staff in the development of lectures and workshops for different aged groups of young people or the public in general.

Ultimately, a major role of the STF would be finding ways in which the many resources of the university and department can be used to stimulate an active interest in the subject from school students of all ages and from the general public. This may be through the organisation of conferences, workshops, competitions, the training of less experienced secondary school teachers of that subject, and in working with academic staff on how to present their research to the wider public. The School Teacher Fellow will have the time to prepare and front numerous activities for which academic staff do not have time because of their teaching and research commitments. They will know the possible pitfalls and the correct level of language appropriate to the courses being taken by the students. In activities that engage teachers as part of professional development it is helpful to have a School Teacher Fellow at least present, if not leading the courses, to put the training into a classroom context. For summer schools a far more ambitious and well thought out approach can be adopted (our experience).

\section{The benefits to a School Teacher Fellow}

There are many secondary school teachers who want to teach, and yet as they progress in seniority the level of teaching, contact with students and the time available to devote to innovative lessons will diminish. Teachers may have ideas they wish to explore, but lack adequate resources to do so effectively. Having the resources, time, technical expertise and equipment allows the development of these ideas. Being a STF can recharge professional batteries. The teachers may develop new skills such as the presenting of lectures to very large audiences. The opportunity to write articles for fellow teachers or for students is also a benefit. STFs can experience new practical techniques and learn new aspects of science, both of which can be used to augment their lessons when back in schools.

\section{The benefits to a school in releasing a School Teacher Fellow}

The benefits are not only to the university or to the teacher concerned. There will be a much stronger relationship between the school and the university which could be of great benefit to a number of the school's teachers and not just the STF. Via the STF the school may be able to access potential funding streams for future school-based projects that were previously unknown. There will also be a substantial amount of Continuing Professional Development (CPD) for one of their 'middle managers' at no cost to the school. The school's own students may be used to pilot ideas, perhaps introducing some students to the possibility of higher education for the first time. Finally, the schools will benefit from more highly skilled teachers on their return.

\section{Acknowledgments}

DES thanks the Higher Education Academy UK for a National Teaching Fellowship and both DES and TGH thank Bristol ChemLabS under whose auspices this work was carried out. Bristol ChemLabS is a HEFCE (Higher Education Funding Council for England) CETL (Centre for Excellence in Teaching and Learning) see http://www.chemlabs.bris.ac.uk/overview.htm for more details. DES is Outreach Director for Bristol ChemLabS and TGH is the School Teacher Fellow. 


\section{References}

Ausubel D.P., (1968), Educational psychology: a cognitive view, New York, Holt, Rinehart and Winston.

Barnes N., (1999), Switching places: why college teachers should teach high school students, Curriculum Inquiry, 29, 293-313.

Rynne E. and Lambert D., (1997), The continuing mismatch between students' undergraduate experiences and the teaching demands of the geography classroom: experience of pre-service secondary geography teachers, Journal of Geography in Higher Education, 21, 65-77.

Wood J. and Morris A., (2005), Report of the working group on physical science and maths education, NERF Working Paper 5.4, December

[http://www.nerf-uk.org/word/5.4PhysicalScience.doc?version=1] 